\title{
A Antífona Virgo Prudentissima de Francisco Gomes da Rocha
}

\author{
Silvio Augusto Crespo Filho
}

Um dos nomes mais destacados entre os músicos das Minas Gerais no século XVIII é o de Francisco Gomes da Rocha. Seus dados biográficos são escassos, como, de resto, os de todos os outros compositores mineiros da época. Sabe-se que nasceu em Vila Rica e atuou com relevância, como compositor e cantor, nas últimas décadas do século, falecendo a 9 de fevereiro de 1808 . Pertenceu ao Regimento de Cavalaria Regular ou de Dragões, o mesmo de Tiradentes, onde desempenhou a função de timbaleiro. Foi também fagotista.

Gomes da Rocha revela mestria refinada e um estilo mais próximo da música européia de sua época do que seus contemporâneos mineiros. Sua obra deve ter sido extensa, embora só algumas raras peças se encontrem hoje nos arquivos de nossa música colonial.

A obra aqui analisada é parte da "Novena de Nossa Senhora do Pilar a 4, com Violinos, Violas, Trompas e Basso" composta em Vila Rica em junho de 1789. Foi das primeiras obras descobertas por Curt Lange, e por ele restaurada e editada. ${ }^{1}$

Esta Antífona assemelha-se a um rondó de uma sinfonia clássica; não propriamente na forma, onde não há estribilho ou reiterações, mas pelo caráter sinfônico, leve e alegre. A forma transparece na quadratura das frases e a harmonia é extremamente clara e definida. Basta dizer que não contém nenhuma função secundária, a não ser uma $\operatorname{Sr} 7$, de passagem. E há apenas uma $\mathrm{S}_{5}^{6}$ e quatro $\mathrm{S} 6 \mathrm{em}$ toda a peça. $\mathrm{O}$ mais são tônicas e dominantes. No entanto, esta simplicidade nos soa riqueza harmônica, tal a mestria no seu uso. A linha lógica, fluente e expressiva do baixo, mostra como a harmonia flui com a melodia e esta com aquela. 
A forma nos tranșmite a imagem de um rondó sem refrão, já que nenhuma secção se repete; aquele papel é desempenhado pelas interligações, cujo material é basicamente sempre o mesmo, em variantes, trazendo junto o motivo unificador, a célula do tema da Introdução. Essas interligações funcionam realmente como "costuras" que unem as diferentes partes da peça ou que as delimitam, devido principalmene à quebra da textura. Não como tranșições modulantes numa estrutura estritamente clássica; as modulações vão se dar no corpo da peça, nos tutti. Também contribuem para a imagem de um rondó as repetições de frases dentro das secções. A forma resulta extremamente coesa pela economia do material temático, com aproveitamento oportuno dos motivos estruturais.

Eis um esboço da macroforma:

$$
\begin{aligned}
& \text { - Introdução - A (Sib) - A'(la) - Cad. (Fa) } \\
& \text { Secção I - A (Sib) - Interlig. - B } \\
& \text { "Quo progrederis" } \\
& \text { Interligação (comps. 25-26) } \\
& \text { Secção II - A (Sib, solo S) - B (Sib coro) - B'(b+b) } \\
& \text { "Quasi aurora Val de rutilans" } \\
& \text { Interligação (comp. 42) } \\
& \text { Secção III - A (Sib, solo C) - B (Sib - fa coro) } \\
& \text { "Filia sim tota formosa et suavis es" } \\
& \text { Interligação (comp. 55) } \\
& \text { Secção IV - A (Fa, solo B) - B (Fa, coro) - B'(Dó, coro) } \\
& \text { "Pulcra ut luna, electa ut sol" } \\
& \text { Interligação (comp. 67) } \\
& \text { Secção V - A(Dó, coro)a A'(Dó, coro)-B(Dó(Fa)-Sib, coro) } \\
& \text { "Pulcra ut luna, electa ut sol" } \\
& \text { C (Sib, coro) - C' (Sib, coro) Cad. } \\
& \mathrm{E} \text { "electa ut sol" 2. }
\end{aligned}
$$

A textura é toda clássica e a introdução instrumental já soa alegremente haydniana. Depois de uma meteórica escala anunciando a tonalidade de Si bemol maior, o tema é exposto quase em uníssono nas 
cordas (a viola faz movimentos inversos). O tema é formado de uma única célula rítmico-melódica de perfil acórdico, ritmicamente a mesma nossa conhecida como "pontuação" da cadência perfeita. Isso será muito importante para a unidade da obra e integração no estilo. A transparência cadencial, a quadratura das frases e a intercambialidade dos componentes do tema são evidentes por si mesmas.

Exposto o tema, volta a escala ascendente do início, ligada a uma semifrase que traz dois motivos importantes: uma cadência e sua pontuação, nada menos que aquela acima mencionada. É já um pouco do próprio material que servirá de interligação, identificado aqui no dinamismo das semicolcheias e dos graus conjuntos da escala.

Exemplo 1 (comp. 6-7)

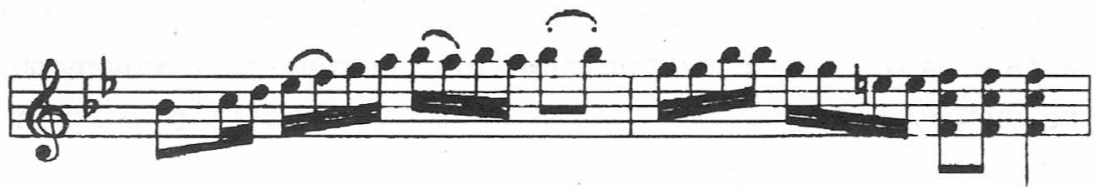

É contrastante com o tema e com as frases do coro e aqui preenche uma função que não terá no decorrer da peça: modulação (para a dominante). Após a repetição do tema, com a diferença de uma célula (que aqui foi utilizada para deixar a abertura de continuidade, antes da vinda do coro). Para encerrar a introdução, volta a frase de interligação, agora melhor identificada pelos movimentos escalares de vai-e-vem, e, ainda uma vez, com a cadência e sua pontuação.

Exemplo 2 (comp. 12-15)

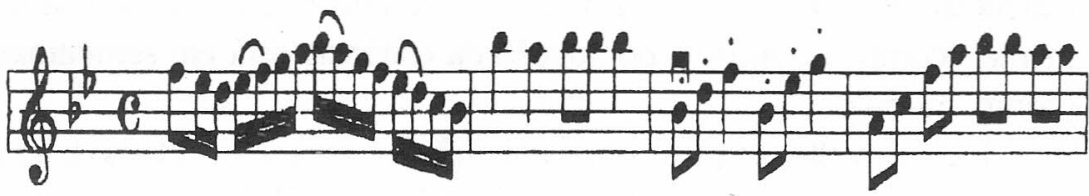

Trêsmotivos do tema ainda se fazem ouvir na entrada dotenor, para se desfazerem no acompanhamento convencional.

Dentro da Secção I também aparece uma variante do material para interligar a parte A com a B, no compasso 20: 
Exemplo 3

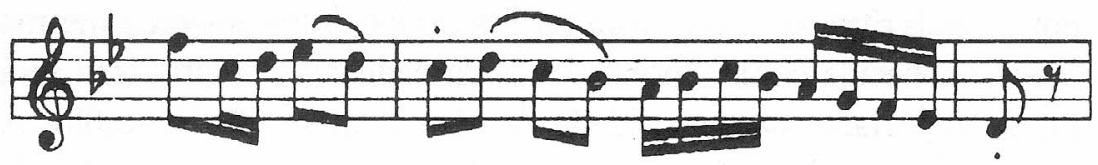

E a mesma escala ascendente do início volta para preencher o vazio entre a parte B e sua repetição ("Quo progrederis"). E da última nota dessa secção surgem, de início, as três células do tema introdutório no II violino com sua inversão no I, para emendarem com as semicolcheias de ligação, que vão introduzir o solo de soprano da Secção II.

Obelo expansivo solo do soprano "Quasi aurora Val derutilans" é acompanhado pelo I violino, no sentido de reforçar a idéia de expansividade expressa na melodia do solo, ao mesmo tempo em que antecipa o motivo que virá no compasso 31. Digna de nota é também a linha do baixo, dentro do mesmo caráter evitando que caia o movimento no compasso 30 (vejam-se o contratempo e as colcheias). O solo termina com uma típica semicadência clássica.

Após a repetição da parte $\mathrm{B}$, volta o elo de interligação, agora com aquele banalizado motivo de cinco notas em oscilação da tônica à dominante e vice-versa, eque doravante vai ganhar sentido crescente no decorrer da obra (comp. 42-49). Ele vem, também, acompanhado das células do primeiro tema, em desenvolvimento no baixo, e penetra a Secção III no solo de contralto "Filia Sion toda formosa". Notar a curiosa sinuosidade do solo $^{3}$ (comp. 43 e ss.) e a cadência típica.

A curta parte B, coral, da Secção III, é uma modulação para a dominante, que conclui sutilmente no I violino com o mesmo motivo cadencial da modulação para a mesma dominante na introdução instrumental (comp. 7). Aqui, a pontuação da cadência está em semínimas (comp. 53-54).

E eis de volta o motivo em semicolcheias, acompanhado no baixo pelo principal motivo unificador, interligando a III à IV Secção ("Pulcra ut luna, electa ut sol' ' - comp. 55-56).

No compasso 60, aquele motivo começa a ser desenvolvido. Ele soa junto com o coro, dentro da Secção III, como se o refrão do rondó viesse ao mesmo tempo que a "estância", e percorre quase todo o 
trecho. A semifrase coral repete-se duas vezes, sendo que numa terceira vez, ao subir um grau, alcança a DDD para modular à dominante da dominante (Dó maior) (comp. 64 e ss.). ${ }^{4}$ Observe-se também o crescimento gradual da tensão e a contribuição dos pedais para isso. Essa tensão serefleteigualmenteno texto, que exibeum conflito na superposição dos dois versos, "pulcra ut luna" e "electa ut sol": na primeira semifrase, as demais vozes se opõem ao baixo; na segunda, o contralto concorda com ele, opondo-se às duas e ficando contra as outras; na terceira, aquele se une novamente às demais vozes, voltando a contrariar no baixo; mas, na última, todos concordam, no momento em que se consuma a modulação, que resolve os conflitos.

Surgindo desse final, e encavalando-se com ele em sua primeira nota, eis de novo o motivo unificador no I violino, em uma variante (exemplo 3a), dando início a outra interligação, que levará à última Secção, a V.

Exemplo 3a

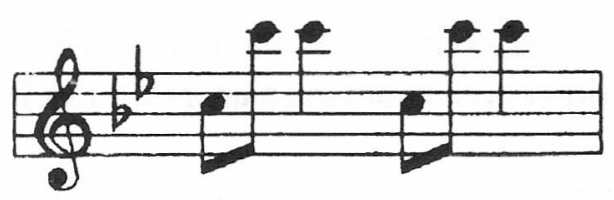

Com relação ao texto, esta Secção continua o desenvolvimento do mesmo versículo, o último ("Pulcra ut luna, electa ut sol"). Ela se estabiliza por alguns compassos em Dó maior, para depois realizar a modulação de volta à tônica. A repetição da mesma frase e de motivos idênticos na primeira semifrase dão esta sensação de um movimento circular e não progressivo. Mas isto será rompido no compasso 77, com a modulação de volta à tônica, até o compasso 80 .

Nesta Secção V, algumas observações se relevam. Por exemplo, a pausa expressiva no coro e no I violino (comp. 70-71) é como um represamento de energia que se desencadeia logo no motivo "nervoso" do mesmo I violino. E este prossegue depois com o que poderia ser uma frase de Manoel Dias no Magnificat (comp. 4-5) ou no Sabbado Sancto deManhã (quem sabe, uma citação?). Note-se também no compasso 73 a pontuação cadencial no I violino, que vem antecedido da (quase) 
inversão do motivo cadencial da modulação no compasso 7, p. 85 , repetido no compasso 53 , p. 94 :

Exemplo 4 e Exemplo 5
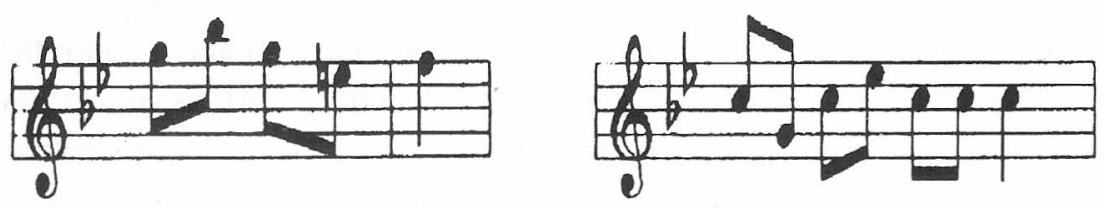

(A pontuação ou codetta da cadência vem aqui sobreposta a uma outra, em semínimas, no baixo, trompas e viola).

Aquela estabilidade em Dó maior era ilusória, porque faltava ainda voltar a Si bemol maior, tônica original. A modulação se dá naúltima frase da Secção (comp. 77-80), tão curta quanto suave, no caminho da menor distância harmônica, conforme a condução exímia do baixo, enquanto as vozes superiores conservam sua planura e o I violino flui pelas notas polares.

Aí, no compasso 80, começa o que poderia ser uma coda, com movimentação periódica de cadências perfeitas e o aumento do ritmo harmônico. E, notável, talvez estejamos diante de uma nova citação (Mozart, $1^{\circ}$ Movimento da Sinfonia no 40, em sol menor):

Exemplo 6 (comp. 80-82)

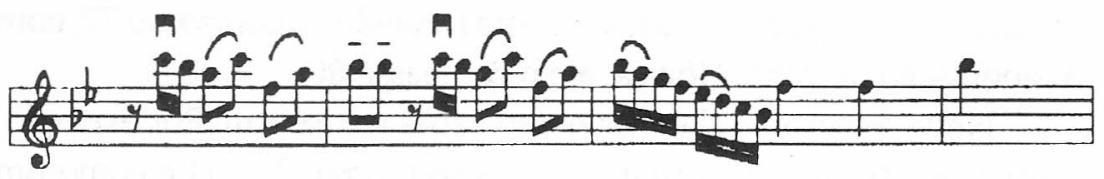

Por fim, a coda da coda, ou melhor, a coda final de todo o movimento, na volta do motivo unificador e da pontuação, ena rebatida do acorde de tônica.

Assim termina esse rondó sui generis, nem barroco nem clássico, talvez proto, pré ... ou paraclássico. Gomes da Rocha pretendeu dar - e 
deu - a esta Antífona, o sentido de conclusão dos finais de sinfonia, uma afirmação ampla da tônica. Mas... uma tônica transposta!

Plano tonal:

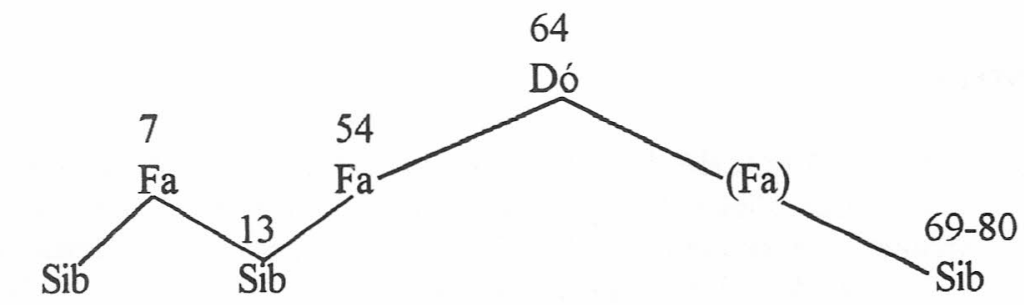

Modulações só na zona superior reforçam o caráter alegre e luminoso impresso no movimento pelo compositor.

Oposições, contrastes e equilíbrio são palavras-chaves desta obra. Contrastes rítmicos e melódicos e suas resoluções no interior das frases, oposições tão clássicas pelo equilíbrio quanto pelas tensões perfeitamente resolvidas no final da frase. Contrastes entre a planura das vozes corais e a ampla movimentação dos violinos e dos solos vocais. Mas também entre os largos arcos melódicos destes e as variações em semicolcheias daqueles.

Seus solos libérrimos nos amplos arcos melódicos em frases desenvoltas, ao contrário daquelas por demais curtas e reiterativas dos sinfonistas de Mannheim.

Impressiona também, em Gomes da Rocha, a autonomia e a liberdade das cordas, com o aproveitamento de motivos melódicos próprios, significativos, variados e desenvolvidos, que se tornam estruturais em nível estritamente estético. E, nos trechos compactos de coral, o perfeito equilíbrio entre baixo e soprano faz com que a massa coral se comporte como um todo, prova de sua estreita intimidade com a harmonia.

Os saltos de trítono e de sétima (mormente nos sopranos e nos solos) junto ao artístico, exímio e original manejo das funções tonais, dentro de impressionante economia do material harmônico e temático revelam, em Gomes da Rocha, a posse da tonalidade em sua essência. Assim, não fora exagero e diríamos que Gomes daRocha funda, com esta 
Novena, um estilo clássico próprio - ainda, ou porque -, sem formasonata.

\section{NOTAS}

1. GOMES DA ROCHA, Francisco. Novena de Nossa Senhora do Pilar, a 4, com Violinos, Violas, Trompas e Basso, 1789. In: LANGE, Francisco Curt. Archivo de musica religiosa de la Capitania de Minas Gerais (Brasil, siglo XVIII) Mendoza: Universidade Nacional de Cuyo, 1951, v.1, p. 33-102.

2. O texto latino diz: "Ó Virgem Prudentíssima / Para onde vais / como aurora tão brilhante? / Filha deSião, és toda formosa e suave, / Bela como a luz, eleita como o sol.'

3. Uma tendência no estilo mineiro da época.

4. Note-se, no final da $2^{\mathrm{a}}$ semifrase, a pontuação cadencial na orquestra.

Sílvio Augusto Crespo Filho é Professor Doutor do Departamento de Música da Escola de Comunicações e Artes da Universidade de São Paulo. 